ÇÜTAD
$\begin{gathered}\text { Çukurova Üniversitesi } \\ \text { Türkoloji Araştırmaları Dergisi }\end{gathered}$

\title{
ESKİ TÜRKÇE AZ SESTEŞ KÖKÜ ÜZERINNE
}

ÖZET

Ahmet KARAMAN ${ }^{1}$

Diller, dış dünyadaki sayısız kavramın karşılanması adına, bazı yöntemlere başvurmaktadır. Çünkü dillerin üretebildikleri sesler sınırlıdır. Bu sebeple, üretilen sesler kullanılarak, sınırsız sayıdaki kavram karşılanmaya çalışılır. Bu gereksinim sonucu dillerin kullandığ 1 yöntemlerden en önemlileri arasında, sözcükler arasında kurulan anlamsal ilişkiler, sözcüklerin yan ve mecaz anlamlar kazanması ve ikileme oluşumu sayılabilir. Kimi durumlarda ise tek bir sözcük hem eş / sesteş hem yan-mecazî anlamlar kazanmış hem de ikileme teşkilinde kullanılmıştır. İşte bu üç yöntemin işlemesiyle, farklı kavramları karşılayan sözcüklerden bir tanesi de $a z$ sözcüğüdür. Eski Türkçe Dönemi’nde, az sözcüğü, sesteş kök özelliği göstererek hem eylem hem ad olarak kullanılmıştır. Dahası az sözcügü eş anlamlar kazanmış olmanın yanında çeşitli ikilemelerin de unsuru olmuştur. Bu yazıda Eski Türkçe Dönemi’nde, $a z$ sözcüğünün tüm anlamsal boyutları incelenecektir. Daha sonrasında ise $a z$ sözcügünün unsuru olduğu ikilemeler saptanacaktır. $A z$ sözcüğünün kazandığ 1 farklı anlamlar ve unsuru olduğu ikilemeler, örnekleriyle birlikte verilecektir.

Anahtar kelimeler: Az / az-, sesteș kök, ikilemeler, eski Türk yazıt ve el yazmalarında ikilemeler, eski Uygur yazmalarında ikilemeler.

\section{ABOUT THE AZ HOMONYM IN OLD TURKIC}

\section{ABSTRACT}

Languages refer to some methods in order to meet the myriad concepts in the external world. Because the voices that languages can produce are limited. For this reason, an unlimited number of concepts are tried to be met by using the sounds produced. There are among the most important methods used by languages as a result of this requirement, semantic relations between words, semantic and metaphorical meanings of words and formation of hendiadyoins. In some cases, a single word has gained both synonyms-homonym and side-metaphorical meanings and has been used in the hendiadyoins.

\footnotetext{
${ }^{1}$ İnönü Üniversitesi, Doktora Öğrencisi. karamana00@gmail.com https://orcid.org/0000-0002-2524-8972.
} 


ÇÜTAD
Haziran 2019 Eski Türkçe $A z$ Sesteş Kökü Üzerine

One of the words that meet the different concepts with the operation of these three methods is the $a z$ word. In the old Turkish period, the $a z$ word was used as both action and name by showing the homonym root feature. What's more, the $a z$ word has been an element of the various hendiadyoins. In this article, all semantic dimensions of the word $a z$ in the Old Turkish period will be examined. Then, the hendiadyoins that are the elements of the word $a z$ are determined. The different meanings of the word $a z$ and hendiadyoins that are the elements of the word $a z$ will be given with examples.

Key words: $\mathrm{Az}$ / Az-, homonym root, reduplication duals / hendiadyoins, hendiadyoins in old Turkish inscriptions and manuscripts, hediadyoins in old Uighur manuscripts.

\section{Gíriș}

Türk dilinin en eski yazılı belgeleri, eski Türk yazısı ile yazılmış yazıtlar ve el yazmalarıdır. Eski Türk yazısı ile taşlara işlenmiş olan bu ilk yazılı belgelerin kimileri II. Türk Kağanlığı ile Ötüken Uygur Kağanlığı dönemlerinden kalma resmi yazıtlar iken kimileri ise Yenisey bölgesinde yaşayan Türk halkının bizzat diktiği mezar taşı yazıtlarıdır. Orta Asya bozkırından Kafkasya'ya oradan da Orta Avrupa'ya dek uzanan topraklarda da bu yazının kullanılmış olduğu bilinmektedir. Söz konusu yazıtlarda kullanılmış olan alfabe, HintAvrupa ve İskandinav kökenli bazı alfabelere benzetilmiştir. Ancak bu benzerlik, o dönemde herhangi bir insanın, eline taşı işlemek için aldığ1 keski-çekiç türünden bir aletle, taşta oluşturabileceği işaretlerin aynılığı kadardır. Zira alfabedeki şekiller aynı olsa bile, bu şekiller aynı sesleri karşılamamaktadır. Türkler 9. ve 10. yüzyıllarda ise artık taşlara işlemek yerine, kâğıt kullanarak da bu yazıyı devam ettirmiştir.

Dış dünyada sayılamayacak derecede varlık bulunmaktadır. Her varlığın ise birbirinden ayırt edilebilecek bir karşılığının bulunması gerekmektedir. Dillerin üretebileceği ses sayısı ortalama 45-50 civarındadır. Bu itibarla, her bir varlık için birbirinden büsbütün farklı kavramların üretilmesi mümkün değildir. İşte bu açmazın giderilebilmesi adına, diller bazı yöntemlere başvurur. Türk dilinin de başvurduğu bu yöntemlerden en önemlileri arasında, sözcükler arasında kurulan anlamsal ilişkiler, sözcüklerin yan ve mecaz anlamlar kazanması ve ikileme oluşumu sayılabilir. Kimi durumlarda ise tek bir sözcük hem eş/sesteş hem yan-mecazî anlamlar kazanmış hem de ikileme teşkilinde kullanılmıştır.

İkileme, anlatılmak istenen duygu ve düşüncelerin aktarım gücünü artırmak, anlatımı / anlamı kolaylaştırmak / pekiştirmek, kavramı zenginleştirmek gibi amaçlarla, aynı kelimenin tekrar edilmesi veya yakın anlamlı yahut zit anlamlı ya da sesleri birbirini 


\section{ÇÜTAD}

benzeyen iki veya daha fazla kelimenin yan yana kullanılmasıdır. İkilemeyi oluşturan kelimeler arasında, anlam ya da ses yönünden benzerlikler bulunmaktadır. İkilemelerin üstlendikleri bir diğer fonksiyon da hiç şüphe yok ki sözü güzelleştirmesidir. Eski Türk yazısıyla yazılmış yazıtlar ve el yazmaları ile eski Uygur Türkçesi metinlerinde bulunan ikilemelere bakıldığında, gerek anlatılmak istenen duygu ve düşüncelerin aktarım gücünü artırmak, gerek anlamı/anlatımı kolaylaştırmak/pekiştirmek gerekse de sözü güzelleştirmek işlevlerinin çalıştığ 1 görülmektedir. İkilemeler oluşurken meydana gelen; anlam değişmeleri, soyutlaşmalar ve mecazî kullanımlar, Türk dilinin, daha o çağda ne derece işlendiğini ve olgunlaştığını göstermektedir. Bu çalışmada, az sözcügünün hem bir adı karşıladığında hem de eylem olarak kullanıldığında, unsuru olduğu ikilemeler semantik açıdan incelenecektir.

Eski Türkçede $a z$ sözcügü sesteş kök niteliği taşımaktadır. Bu noktada, ortak kök ile sesteş kök kavramları birbirine karıştırılmaktadır. Ortak kökler, hem yazılış itibarıyla hem de anlamsal olarak birbiriyle ilgili köklerdir. Sesteş kökler ise yazılış itibarıyla aynı olmakla birlikte aralarında anlamsal hiçbir ilginin bulunmadığı köklerdir. Az sözcügü sesteş kök olmanın yanında, yan ve mecaz anlamlar da kazanmıştır. Eski Türkçede $a z$ sözcüğü, eylem olarak kullanıldığında da bir adı karşıladığında birden fazla anlama gelecek şekilde kullanılmıştır. Ayrıca az sözcüğü bazı ikilemelerin de unsuru olmuştur. Yapılacak bu çalışmada, az sözcüğünün unsuru olduğu ikilemelerin, anlamsal boyutlarının ortaya konulması, Eski Türkçe Dönemi'ne ait metinlerin daha iyi anlamlandırılması noktasında da katkılar sunacaktır. Bu yazıda, söz konusu farklı anlamlar, eski Türkçedeki örnek kullanımlarıyla birlikte derinlemesine incelenecektir.

Türkçenin ilk yazılı belgeleri, farklı bağlamları içerdiğinden, her metinde eski Türkçeye ait değişik sözcükler yer almaktadır. Bu bakımdan, Eski Türkçe Dönemi'ni konu alan çalışmalarda, bütüncül bir araştırmaya ihtiyaç vardır. Bu yazının konusu olan $a z$ sözcüğünün, eski Türkçedeki farklı anlamsal boyutlarının daha iyi bir biçimde ortaya konulabilmesi adına, az sözcügüü, eski Türk yazısıyla yazılmış yazıtlar, el yazmaları, eski Uygur Türkçesi ve Karahanlı Dönemi metinlerinin tamamında aranacaktır. Türk dilinin Eski Türkçe Dönemi'nin bir parçası olan Karahanlı Türkçesi metinlerinde de $a z$ sözcügünün farklı kullanımları eğer varsa tespit edilecektir. 


ÇÜTAD
Haziran 2019 Eski Türkçe $A z$ Sesteş Kökü Üzerine

\section{Ad Olarak $A z$}

\section{1. ‘Çok, Fazla Olmayan / Biraz’ Anlamında Az}

$A z$ sözcüğü eski Türk yazısıyla yazılmış yazıtlar incelendiğinde; II. Türk Kağanlığından kalan, Köl Tegin, Bilge Kağan, Bilge Tonyukuk, Ongin, Küli Çor ile Ötüken Uygurlarından kalan Șine Usu yazıtlarında ve el yazması eserlerden Irk Bitig'de 'çok, fazla olmayan / biraz' anlamında kullanılmıştır. Sözcüğün eski Türkçedeki temel anlamı budur. Sözcük, Yenisey bölgesi, Dağlık Altay Cumhuriyeti ve Kırgızistan yazıtlarında, bu anlama gelecek şekilde saptanmamıştır. Eski Uygur Türkçesi metinleri ile Karahanlı Dönemi eserlerinde de bu anlamın devam ettiği görülmektedir. Sözcügün bu anlamını içeren birkaç örnek aşağıda verilmiştir: ${ }^{2}$

[...] çıgañ bodunug bay kıltım az bodunug üküss kıltım [...] "Yoksul halkı zengin ettim. Az halkı çoğalttım." [KT, G 10] (Aydın, 2017, s. $50)$.

üküş téyin neke korkur biz az téyin ne basinalım tegelim [...] “(sayıları) çok diye niye korkuyoruz? Azız diye yenilecek miyiz? Saldıralım.” [T B 4] (Aydın, 2017, s. 114).

[...] éşi yér tapa az er $\imath<d>$ tım [...] "Müttefiklerin yerine doğru az adam gönderdim." [ŞU D 11] (Aydın, 2018, s. 58).

[...] ança biligler bo ırk başınta az emgeki bar [...] "Öylece biliniz ki bu falın başında (az) biraz sıkıntı vardır." [Irk Bitig 57] (Yıldırım, 2017, s. 47).

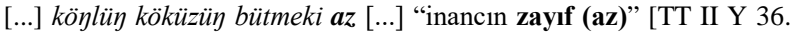
14, 83] (Bang W. ve Gabain A. von, 1929, s. 248).

[...] bay barımlıg tınlıglar az yok çıgay tınlıglar üküş [...] "Zengin insanlar az, yoksul insanlarsa çok” [TT VI, Sekiz Yükmek, 024] (Bang W. vd. 1934, s. 106).

$A z$ sözcügü, eski Uygur Türkçesi verimlerinden Kşanti Kılguluk Nom Bitig'de yuka sözcüğüyle birlikte az yuka ikilemesinin unsuru olmuştur. Bu ikilemenin anlamı ise 'az, sı̆ / çok derin olmayan' olarak ifade edilebilir.

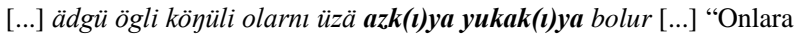
karşı iyiliği, azıcık olur” [Kşanti Kılguluk Nom Bitig, BTT XXV, 295] (Wilkens, 2007, s. 70).

\footnotetext{
${ }^{2}$ Daha fazla bilgi için ayrıca $b k$. ED 277a.
} 


ÇÜTAD
Haziran 2019 Eski Türkçe $A z$ Sesteş Kökü Üzerine

\subsection{Bir Boy Adı Olarak $A z$}

Orta Asya bozkırlarında, Köktürkler çağında yaşamış olan bu halk hakkında yeterli bilgi bulunmamaktadır. Dahası $A z$ ifadesiyle bir soy adının mı yoksa boy adının $m ı$ ifade edildiği dahi belli değildir. Azların, Yenisey Irmağı'nın batı veya sol kıyıları ile, Alaş akarsuyu Bay-Tayga yöresi civarında yaşamış oldukları düşünülmektedir. Azların lideri ise İlteber unvanını kullanmıştır ${ }^{3}$. Bu boy adı, II. Türk Kağanlığı'ndan kalan, Köl Tegin, Bilge Kağan, Bilge Tonyukuk, Küli Çor ve Uygurlara ait Tariat (Terh) yazıtları ile E 68 numaralı Yenisey bölgesi yazıtı olan El-Bajı yazıtında tanıklanmıştır. Dağlık Altay Cumhuriyeti ve Kırgızistan yazıtları ile eski Türk yazısıyla yazılmış el yazmaları, eski Uygur metinleri ve Karahanlı Dönemi eserlerinde, bu kavim adı yer almamaktadır.

[...] az bodunug étip yar[atıp] [...] "Az halkını düzene sokup örgütleyerek” [KT D 19] (Aydın, 2017, s. 57).

[...] çölgi az eri bultum éşi $<d>$ tim az yér $y^{2}[o l ı]$ anı b[irle] ermiş [...] "Bozkır Azlarından bir adam buldum. (Şöyle) işittim: "Az ülkesinin yolu Anı (Irmağı) boyunda? imiş.” [T D 6-7] (Aydın, 2017, s. 110).

[...] tenri kanım atligı tokuz tatar yéti yégirmi az buyrukı toyrad ${ }^{2} a$ sejüt bıңa [...] "İlahi (yüce) hanımın atlıları (süvari birliği) Dokuz Tatar(lardan) on yedi, Az(lardan) komutanlar, Tongra(lardan) generaller ve süvari birliğinden (oluşuyordu). [Ta K 2] (Aydın, 2018, s. 47).

[...] az totog ançındanga? $k^{1}<\ldots>[\ldots]$ “Az(ların) askeri valisi $<\ldots>$ ” [El-Baj1 13] (Aydın, 2019, s. 181-182-183).

\subsection{Bir Hayvan Adı Olarak Az}

Zoolojide mustela erminea olarak bilenen, sansargillerden, yazın esmer kırmızı, kışın beyaz renkli kürkü ile değerli olup etçil bir hayvan olan kakım, eski Türk yazıtlarında hem az hem de as şeklinde geçmektedir. Eski Türkçede $a z$ / as olarak geçen bu hayvanın sözlüklerdeki karşılığı olarak gösterilen 'kakım' sözcüğünün kökeni ise Arapçadır ${ }^{4}$. Bu hayvan adı, eski Türk yazıtları içerisinde, yalnızca Dağlık Altay Cumhuriyeti yazıtlarından A 85 numaralı İnegen yazıtı ile Yenisey bölgesi yazıtı olan E 98 numaralı Uybat VI ve E 123 numaralı Tepsey VIII yazıtlarında tanıklanmıştır. İnegen ve Uybat VI

\footnotetext{
${ }^{3}$ Daha fazla bilgi için ayrıca bk. Aydın, 2018, s. 102; Aydın, 2015, s. 138; Aydın, 2011, s. 392; Aydın, 2008, s. 98; Golden, 2002, s. 115; Ölmez, 1997, s. 175.

${ }^{4}$ As hakkında ayrica $b k$. ED 240a.
} 
yazıtlarında as olarak geçen sözcük, Tepsey VIII yazıtında $a z$ biçimindedir. Eski Uygur metinlerinde ise bu hayvan adı geçmemektedir. Kaşgarlı ise DLT'nin az bahsinde, as, kakım, şin'li şekli de vardır ve o daha doğrudur, demektedir. As bahsinde ise as, kakım, Ze'li şekli de vardır, bu kelimeyle cariyeler adlandırılır, demektedir (Ercilasun - Akkoyunlu, 2015, s. 38).

g? ay külüg az a irbiş $e$ "(Adım) Ay Külüg. Kakım ve Sibirya panteri.” [E. 123. Tepsey VIII] (Aydın, 2019, s. 219).

\section{4. 'Arzu, Heves, Hirs, Tutku' Anlamında Az}

$A z$ sözcügünün bu anlamı, eski Türk yazısıyla yazılmış yazıt ve el yazmaları ile Karahanlı Dönemi metinlerinde görülmemektedir. Eski Uygur metinlerinde ise sinırlı sayıda kullanımı vardır. Dahası, az sözcüğü bu anlamıyla tek başına değil; nızvanı, amranmak, övke, suk ve armıl sözcükleriyle birlikte kullanılmıştır. $A z$ sözcüğü, anılan bu sözcüklerle birlikte, ikileme teşkilinde kullanılmıştır. Eş ya da yakın anlamları karşılamak için kurulmuş olan söz konusu ikilemeler örnekleriyle birlikte aşağıda verilmiştir.

\subsection{1. az nizvant}

Nizvanı sözcüğü, tıpk1 az sözcüğü gibi 'hırs, tutku, heves' anlamına gelmektedir. Eş anlamlara gelen bu iki sözcük, az nızvanı ikilmesinin unsuru olmuştur. Herhangi bir şey için duyulan; aşırı isteğin, hevesin, arzunun bir ifadesi olan bu ikilemenin görüldüğü yerler aşağıda verilmiştir:

[...] tavar buşı yalayuz az nızvanıg ok kever küçsiretür [...] "Mal sadakası yalnızca (aşırı) hırs (ve) tutkuyu zayıflatır güçsüzleştirir.” [A. Y., III. Teg., 163 (III. 19a), 10] (Kaya, 1994, s. 131).

[...] az nızvanıka agukup artayu yokadtururta [...] "(Aşırı) arzu (ve) heveslerle zehirlenerek bozulup kendini kaybetmek üzereyken” [7. Büyük İlâhî (Mani İçin)] (Arat, 1991, s. 40), [T III D 259 22, 260 32, 28] (Bang W., Gabain A. von, 1930, s. 186).

[...] ogrılarnıy birin az nızvanı ogrınta ölörmiş [...] "Hırsızların biri (aşırı) hırs (ve) tutku uğrunda öldürmüş” [T II D 178b 180, 19-20] (Bang W. ve Gabain A. von, 1929, s. 424).

[...] az nızvanıka ersikip ayıg kılınç üküş kıltımız [...] “(Aşırı) hırs (ve) tutkuya iğrenip çokça iyi amel işledik" [BTT XIII, 16. Metin, 39] (Zieme, 1985, s. 109). 
Eski Uygur Türkçesi metinlerinden Kşanti Kılguluk Nom Bitig'de bir de az nızvanılıg ikilemesi vardır. Bu ikileme ise '(aşırı) hırs (ve) açgözlülük, tutkulu olma' şeklinde anlamlandırılabilir.

[...] az nızvanılıg ämgäklig taloyda uzatı [är]käçlänürlär [...] “(Aşırı) hırs (ve) açgözlülük acısıyla okyanusta uzun süre sürüklenirler” [Kşanti Kilguluk Nom Bitig, BTT XXV, 387]. (Wilkens, 2007, s. 76).

\subsection{2. az amranmak}

Amranmak sözcüğü aslında 'sevgi, aşk, sevinç, sevmek' anlamlarına gelmektedir (Caferoğlu, 2015, s. 14). Ancak az sözcügüyle birlikte oluşturduğu ikilemenin anlamı, 'bir şeye duyulan karşıkonulamaz istek, hırs, tutku, açgözlülük' olarak ifade edilebilir. Amranmak sözcüğü, söz konusu ikilemenin içinde 'isteğin aşırısı, tutkunun öçgözlülüğe dönüşmesi’ anlamını karşılamaktadır.

[...] tavar buşı yalayuz az amranmak uguş yértinçüdin yme üntürü ermez [...] "Mal sadakası yalnızca (aşırı) hırs (ve) açgözlülük hakim olan bölgeden kurtarmaz.” [A. Y., III. Teg., 162 (III. 18b), 21] (Kaya, 1994, s. 131).

[...] az amranmak köyül agulug yılanka okşayur [...] “(Aşırı) hırs (ve) açgözlülük zehirli yılana benzer" [BTT I, B, 11. Yaprak, 1 (65)] (Hazai - Zieme, 1971, s. 23).

[...] az amranmak bo köyüllüg alkuta ınaru tıdıylar [...] "Her şeyden önce (aşırı) hırs (ve) açgözlülüğü engellemek gerekir” [BTT XIII, 15. Metin, 21] (Zieme, 1985, s. 107).

[...] ymä az amranmak üzä [...] "Yine (aşırı) hırs (ve) açgözlülük üzerine" [Kşanti Kılguluk Nom Bitig, BTT XXV, 1586] (Wilkens, 2007, s. 156).

Az nızvanı ve az amranmak ikilemelerinin, Altun Yaruk'un 3. kitabının birbirine yakın satırlarında görülmesi dikkat çekicidir. İki ikileme de benzer anlamlara gelmektedir. Her iki ikilemenin esas unsuru $a z$ sözcüğüdür. $A z$ sözcüğünün 'aşırı istek, tutku, hırs' anlamı, nızvanı ve amranmak sözcükleriyle birlikte kullanılarak oluşturulan ikilemeyle pekiştirilmiştir.

\subsection{3. az övke / azlı övkeli / azsız övkesiz}

$A z$ sözcügünün sözü edilen 'hırs tutku' anlamıyla, övke sözcüğü arasında, ilk bakışta zorlama gibi görünen anlamsal ilişki, aynı ikilemenin unsuru oldukları görüldüğünde ortaya çıkmaktadır. 'Bir şeye duyulan aşırı istek, arzu, heves, hırs' sonucunda, kişide öfke uyanmaktadır. Bu itibarla, eski Uygur edebiyatında, aşırı hırs ve 
sonucunda oluşan öfke, az övke ikilemesiyle ifade edilmiştir. Söz konusu ikilemenin bir başka anlamının da az sözcüğünün, yazının ilerleyen bölümlerinde değinilecek olan 'yoldan çıkmak' anlamıyla paralel olarak 'azmış, yoldan çıkmış' olduğu söylenebilir. İkilemenin, 'hırslı öfkeli', 'hırssız öfkesiz' anlamlarını karşılayan örnekleri de aşağıda belirtilmiştir.

[...] adınlarnıy az övke biligsiz küni küvenç körüm sizik ulatı nızvanıları teprep [...] "Başkalarının hırs öfke, yersiz kıskançlık, gurur (dolu) bakış, kuşku (ve) ilaveten (aşırı) tutkularını sarsarak” [A. Y., IV. Teg., 229 (IV. 15a.), 16] (Kaya, 1994, s. 159).

[...] az övke biligsiz küni küvenç körüm sizikde ulatı kamag nızvanılar erür [...] "Hırs öfke, yersiz kıskançlık, gurur (dolu) bakış, kuşkular (ve) ilaveten tüm hırslar bulunur" [A. Y., IV. Teg., 243 (IV. 22a.), 23] (Kaya, 1994, s. 164).

[...] biligsiz az övke küvemç togarlar belgülerler [...] "Yersiz hırs öfke (ve) gurur doğar, oluşur " [A. Y., IV. Teg., 247 (IV. 24a.), 6] (Kaya, 1994, s. 166).

[...] basa yana az övkeler biligsiztin [...] "Aynı zamanda hırs öfke ve bilgisizlikten dolayı” [14 A. İnanç] (Arat, 1991, s. 150).

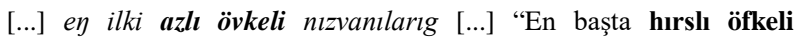
tutkuları” [A. Y., IV. Teg., 225 (IV. 13a.), 9] (Kaya, 1994, s. 157).

[...] azsız övkesiz biligsiz bo üç törlüg [...] "Hırssız öfkesiz yersiz bu üç türlü” [A. Y., IV. Teg., 241 (IV. 21a.), 21] (Kaya, 1994, s. 164).

[...] tınlıglarnıy azsız övkesiz biligsiz [...] "Canlıların hırssız öfkesiz yersiz” [A. Y., IV. Teg., 243 (IV. 22a.), 4] (Kaya, 1994, s. 164).

\subsection{4. azsız suksuz}

Suk sözcüğü tıpkı az, nızvanı ve amranmak sözcüğü gibi 'ihtiras, heves, istek' anlamına gelmektedir. Yine, $a z$ sözcüğünün bu anlamıyla birlikte kullanılarak ikileme oluşturulmuştur. Eski Uygur edebiyatında, az suk olarak değil, olumsuz şekli olan azsız suksuz biçimi tanıklanmıştır. Bu ikilemenin anlamı 'hırssız ihtirassız, tok gönüllü’ olarak ifade edilebilir.

[...] kök kalık teg yuklunmaksız azsız suksuz [...] "Gökyüzü gibi bulaşılmaz hırssız ihtirassız” [15. Hikmet Fazileti] (Arat, 1991, s. 156). 


\subsection{5. azsız esirkençsiz}

Kşanti Kılguluk Nom Bitig'de azsız suksuz ikilemesiyle benzer anlama gelen azsız esirkençsiz ikilemesi geçmektedir. Bu ikileme, 'aşırı tutkuya, hırsa, açgözlülüğe düşmeyen, eli açık, cömert' anlamına gelmektedir:

[...] azsız äsirkänçsiz köyülüg <:> ulug köyülüg [...] “Cömert yüreği / cömertliği, büyük yüreği / büyük yardımserliği [Kşanti Kılguluk Nom Bitig, BTT XXV, 3227-3228]. (Wilkens, 2007, s. 246).

\subsection{6. az armil/almir}

Armıl / almır sözcüğü eski Uygur metinlerinde tek başına sınırlı sayıda tanıklanmıştır. Söz konusu sözcük, özellikle az armıl / almır ikilemesininin bir unsuru olarak az sözcüğü ile birlikte kullanılmıştır. Armıl / almır sözcüğü, az sözcüğünün 'hırs, istek, arzu' anlamının eş anlamlısı gibi görünmektedir. ${ }^{5}$

[...] övke az armıl kılınçı artuk küçlüg erip [...] "Öfke hırs tutku (dolu) ameli çok güçlü k1lıp” [TT VI, Sekiz Yükmek, 71] (Bang W. vd. 1934, s. 110).

[...] az almır bolmasar [...] [44a. 10 = 110a, 15] "Hurs (ve) tutku dolu olmasa" (Tekin, Maytrısimit, s. 98).

[...] az almır bolmaz [...] "Hirs (ve) tutku dolu olmaz" [44a. $10=$ 110a, 16-17] (Tekin, Maytrisimit, s. 98).

[...] biz yime az almır köyülümüz küçlüg bolup [...] "Biz yine, hırs (ve) tutku dolu gönlümüz ağır basıp" [72. 5 = 13320 187, arka 47-48] (Tekin, Maytrısimit, s. 136).

\subsection{7. az saran}

$A z$ ismiyle kurulan bu ikilemelerden başka, anlamı tartışmalı bir de az saran ikilemesi vardır. Clauson saran sözcüğü için, 'miser, miserly (cimri, tamahkâr)' anlamını verir (ED 853b, 854a). A. Caferoğlu sözlüğünde saran sözcüğünün karşılığı olarak, 'eli sık1, hasis, cimri’ karşılığını verir (2015, s. 197). Saran sözcüğü Karahanlı Dönemi eserlerinde de 'cimri' anlamında kullanılmıştır. Serkan Şen'in yüksek lisans tezi olan Eski Uygur Türkçesinde İkilemeler adlı çalışmada, az saran ikilemesi 'aç gözlü hasis' olarak verilmiştir (Şen, 2002, s. 48). M. Ölmez de aynı konuyla ilgili yaptığı çalışmada $a z$

${ }^{5}$ Ş. Tekin sözcüğü almır olarak okur ve ikilemeyi de az almır olarak verir (Tekin, 1976, s. 98). Armıl için ayrıca bk. ED $146 b$. 
saran için, 'haset ve cimri, kıskanç ve pinti' anlamını verir (Ölmez, 2017, s. 243-311). Gerek Şen'in gerekse de Ölmez'in yapmış oldukları bu anlamlandırmaların nedeni, saran sözcügüyle $a z$ sözcüğü arasında anlam ilişki kurmalarıdır. Bundan başka, az sözcüğünün bu tip bir 'kıskançlık' anlamını içerdiği örnek tanıklanmamıştır. Yalnız Altun Yaruk'ta geçen, azlanma- künileme- ikilemesinin anlamını, 'kıskanmak' anlamındaki künile- sözünden hareketle 'kıskanmak' olarak tespit etmek mümkün olabilir. Bu itibarla, az sözcüğünün yukarıda belirtilen ikilemelerde de görülen, 'tutku, arzu, hırs' anlamı göz önüne alınarak az saran ikilemesinin, 'hırslı cimri' olarak karşılanması daha doğru gibi görünmektedir. Bu durumda, kötü izlenimler uyandıran, 'bir şeye duyulan aşırı istek, tutku, arzu, hırs ile cimrilik, eli sıkılık' arasında anlam ilişkisi kurularak az saran ikilemesi oluşturulmuştur. Bu tip kötü özelliklerin yan yana anılarak kişinin bunlardan kurtulmasının öneminin vurgulanması, eski Uygur metinlerinde sık karşılaşılan bir durumdur. Ayrıca $a z$ sözcüğünün kazandığı bu 'cimrilik' anlamı azlan- kıvırgaklan- eş anlamlı ikilemesinde de görülebilir. Zira azlan- kıvırgaklan- ikilemesi de 'cimrilik, pintilik etmek' anlamına gelmektedir.

[...] emgek tözlüg az saran köyülümüzni tarkaru kéterü [...] "Sı1kıntı esaslı, hırslı cimri gönlümüzü (bu duygulardan) uzaklaştırarak (bu duyguları) dağıtarak" [A. Y., VII. Teg., 472. (VII. 7b), 4] (Kaya, 1994, s. 263).

[...] ol kişi az saran köyül turgurguluk ermez [...] "O kişi hırslı cimri gönlünü (bu duygulardan) kurtaramaz.” [A. Y., VIII. Teg., 526. (VIII. 15b), 16] (Kaya, 1994, s. 285).

$A z$ adı yukarıda ifade edilen anlamlarının yanında, bir de II. Türk Kağanlığı'ndan kalan Köl Tegin yazıtının kuzey yüzünün beşinci ve sekizinci satırlarında tanıklanmıştır.

[...] köl tégin az yagızın² binip oplayu tegip [...] “Köl Tegin Az yağız (atına) binip ileri atılıp saldırı"” (Aydın, 2017, s. 66).

[...] köl tégin az yagızın² binip tegdi [...] "Köl Tegin Az yağız (atına) binip saldırdı.” (Aydın, 2017, s. 66-67).

Satırlar incelendiğinde, az yagız ifadesinden ya Köl Tegin'e ait bir atın ismi, rengi ya da cinsi anlaşılmaktadır. Buradaki yagız sözcüğ̈̈ 'kahverengi' anlamınada bir sözcüktür ve atın rengini belirtir. Atın rengini ifade eden bu yagız sözcügünün Moğolca karşılığı ise 'dajir'dir. Az yagız ifadesini 'Az halkına ait kahverengi / toprak rengi at' olarak anlamak daha doğru gibi görünmektedir. Çünkü bozkır yaşamında hem Moğollar hem de Türkler atları renklerine göre 
isimlendiriyorlardı. Yagız atın rengini ifade ettiğine göre $a z$ da bu atın adını yahut alındığı yeri ifade etmelidir. ${ }^{6}$

\section{Eylem Olarak Az-}

\section{1. 'Şaşırmak, Sapmak, Yoldan Çıkmak, Yolunu} Kaybetmek' Anlamında Az-

Az- eylemi, eski Türk yazısıyla yazılmış el yazmalarında, sıklıkla bu anlamıyla kullanılmıştır. II. Türk Kağanlığı'ndan kalan yazıtlardan Ongi yazıtında, söz konusu 'şaşırmak, sapmak' anlamının olumsuz şekli kullanılmıştır. Az- eylemi, bu anlamıyla eski Uygur ve Karahanlı Türkçesi metinlerinde de tanıklanmıştır.

[...] azmasun tép yérçi yarat $<t>l$ yayılmazun tép bilgeg urtı azmaz yé[r]çi yayılmaz bilge unıtm[m]az ötügçi yayılmaz bétkeçi bilgelig yayılmaz yérçilig azmaz yayılmasar bilge bol[maz] azmasar yérçi bolmaz [...] "Yolu kaybetmesin diye kılavuz yarattı, yanılmasin diye bilge meydana .çıkardı. Yoldan çıkmayan kılavuz(dur), yanılmayan bilge(dir), unutmayan ricacı(dır), yanılmayan yazıcı(dır). Bilgesi (danışması) olan yanılmaz, kılavuzu olan yolunu kaybetmez.Yanılan olmasa bilge olmaz, yolunu kaybeden olmasa k1lavuz olmaz." (Or. 8212/78 A Fragmanı: A (B?) Yüzü, 6, 8, 13).

[...] üze tuman turdl asra toz turdı kuş og $<l>l$ uça azt kéyik ogll yügürü aztı kişi oglı yorıyu aztı [...] "Yukarıdan sis bastırdı, aşağıdan toz kalktı. Kuş yavrusu uçarken yolunu kaybetti. (Dört ayaklı) yabanî hayvan yavrusu koşarken yolunu kaybetti. İnsanoğlu yürürken yolunu kaybetti.” [Irk Bitig 15] (Yıldırım, 2017, s. 36).

[...] yol azsar ev tapmaz [...] "yolu şaşırsa evi bulamaz” [T II Y 36. 13, 33] (Bang W. ve Gabain A. von, 1929, s. 246).

[...] azmışlarka yolçı yértçi boltujuz [...] “(yolunu) şaşırmışlara rehber k1lavuz oldunuz.” [T III D 260 3, 69] (Bang W. ve Gabain A. von, 1930, s. 190).

DLT'de ise az- bahsinde, ol yol azdı "o yolu kaybetti, şaşırdı." denilmektedir. (Ercilasun - Akkoyunlu, 2015, s. 89). Ula maddesinin örneğinde ise ula bolsa yol azmas bilig bolsa söz yazmas "Arazide işaret olsa yol kaybedilmez; insanda da akıl olsa konuşmada yanlış yapmaz.” denilmektedir (Ercilasun - Akkoyunlu, 2015, s. 44). Az-

\footnotetext{
${ }^{6}$ At adları ve renkleri konusunda daha fazla bilgi için $b k$. ED 909a, Doerfer, 1995, ss. 208-227; Sağol, 1995, ss. 126-146; Aalto, 2000, ss. 453-457; Clauson, 1965, ss. 161-166; Esin, 1965, ss. 167-227.
} 
eylemi bu anlamıyla, Karahanlı Dönemi eserlerinden Kutadgu Bilig, Divân-1 Hikmet ve Kur’an Tercümesi’nde de kullanılmıştır.

\section{2. ‘Ayrılmak, Çekip Gitmek, Ölmek’ Anlamında Az-}

Az- eylemi, Yenisey bölgesi mezar taşı yazıtlarında, mecazî bir kullanımla, 'kişinin bu dünyadan ayrılması, ölmesi' anlamını kazanmıştır. Sözcük, 'kişinin yolunu şaşırarak bu dünyadan göçmesi, sevdiklerinden ayrılması' anlamında kullanılmıştır.

kün e ay a azdım "güneşten aydan ayrıldım." [E. 11. Begre, 2] (Aydın, 2019, s. 70).

sekiz adaglıg barımıg üçün yılkı tüketi bardım a anta bökmedin e yıta ürüyümüg e karamig a azdım a "Sekiz ayaklı malım mülküm için, at sürüm tükeninceye kadar gittim. Onlara doymadım, ne acı! Soylu (ve) avam (halkımdan) ayrıldım.” [E. 11. Begre, 3] (Aydın, 2019, s. 70).

élim e kanım a bökmedim e yaşım yéti yétmiş azdım a "Yurduma, hanıma doymadım, Yaşım altmış yedi (iken) ayrıldım (öldüm).” [E 11. Begre 6] (Aydın, 2019, s. 70).

bir yétmiş yaşımga kök teyride künke azdım esizim e "Altmış bir yaşımda mavi gökteki güneşten ayrıldım. Ne yazık!" [E. 45. Köjeelig-Hovu, 5] (Aydın, 2019, s. 151).

$<\ldots>t^{2}$ oglum öz er azdım "< $<>$ çocuklarım < ..> ayrıldım.” [E. 68. El-Baj1, 12] (Aydın, 2019, s. 182).

üç arguy art $<d>$ Im esizim e adrl $<l>$ tım a bökmedim e azmatım ay $k \ddot{u}[n]<\ldots>$ "Üç siperi artırdım, ne yazık ki ayrıldım. (Sizlere) doymadım, ayrılmadım, ay (ve) güneş <... ” [E. 42. Bay-Bulun I, 4] (Aydın, 2019, s. 142).

Yenisey bölgesi yazıtlarında, E 2 numaralı Uyuk-Arjan yazıtının ilk satırında bir de azış- eylemi tanıklanmıştır. Azış- eylemi de tıpkı $a z$ - eyleminin verdiği 'ayrılmak, ölmek' anlamını taşımaktadır.

éşim <u>rım azış̧ım "Eşim(den) çocuklarım(dan), ayrıldım." (Aydın, 2019, s. 47).

Az- eyleminin kazandığı bu mecazî 'ölüm' anlamı, eski Türk yazısıyla yazılmış yazıtlar, el yazmaları, eski Uygur Türkçesi ile Karahanlı Dönemi metinleri içerisinde, Yenisey yazıtlarından başka, Dağlık Altay Cumhuriyeti yazıtlarından A 7 Mendur-Sokkon 1-2 ve A 18 Bar-Burgazı I yazıtlarında tanıklanmıştır.

A 7 numaralı Mendur-Sokkon 1-2 yazıtının ilk satırında: 
er (a)t(l) (a)t(a)r (a)pa ak yaddın öl(ü)p (a)z(a)r (e)rk(i)m[n]i ? (e)l(i)g (a)d(a)s(l)m ad(i)r(i)p öz (e)w(i)me /(e)w(i)ne t(e)z(i)tdi "Erkeklik adı Atar Apa('dır). (O) Nefret dolu yabancılar yüzünden öldü. Elli yoldaşımın gücünü (benden) ayırıp evime / evine (obama/obasına) kaçmak zorunda bıraktı. / Erkeklik adı Atar Apa('dır). (O) Nefret dolu yabancılar yüzünden öldü. Elli yoldaşımı

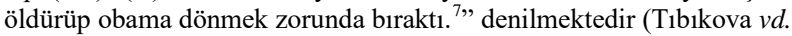
2012, ss. 131-132; http://www.altay.uni-frankfurt.de/A7/A7_O.HTM, 05.10.2018).

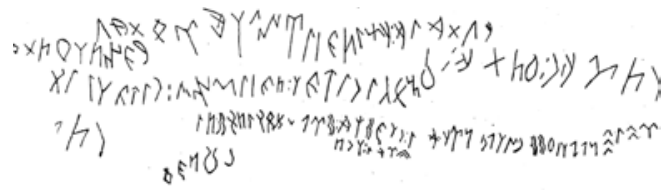

[Fotoğraf 1: http://www.altay.uni-

frankfurt.de/A7/MENSOK1_X.PNG (05.10.2018)]

A 18 numaralı Bar-Burgazı I yazıtında da:

ünt(e) (e)s(i)z(i)m e : éki (a)t (a)zd(u)rtı : kuyda $k(i) s(i)(\eta>m) e$ (a)dr(l)lt(l)m "Bağır! (Yas tut!) Ne yazık! Ne acı! İki at öldürüldü, obada eşimden ayrıldım (öldüm)." denilmektedir (Tıbıkova vd. 2012, ss. 109-110-111; http://www.altay.uni-frankfurt.de/A18/A18_O.HTM, 05.10.2018).

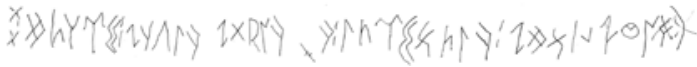

[Fotoğraf 2: http://www.altay.unifrankfurt.de/A18/BRBGZ1_X.PNG (05.10.2018)]

Yazıtta geçen $a z-$ eyleminin, mecazî ölüm anlamı taşıdığı açıkça görülmektedir. Sözcük, -tUr- ettirgenlik eki alarak sözü edilen iki atın öldürülmüş olduğunu ifade etmiştir ${ }^{8}$.

\footnotetext{
${ }^{7}$ Farklı bir anlamlandırma denemesi için ayrıca bakınız: Kormuşin vd. 2016, s. 295.

${ }^{8}$ Farklı okuma denemeleri için yukarıda verilen internet adresine bakılabilir, ayrıca: Kormuşin vd. 2016, s. 282.
} 


\subsection{Az- Eylemiyle Kurulan İkilemeler}

$A z$ - eylemi de tıpkı az adı gibi yalnızca eşseslilik, eş anlamlılık ve mecazî anlam kazanmanın yanında, ikileme teşekkülünde de kullanılmıştır.

\subsection{1. az-yayıl-}

Az- sözcüğü ile yayıl- sözcüğü yan yana kullanılarak 'şaşırmak, yoldan çıkmak' anlamında, yakın anlamlı bir ikileme oluşturulmuştur. Burada söz konusu ‘yolunu kaybetmek' anlamı mecazidir:

[...] altı yollug sansarta azıp yayılp tägzinür [...] "Altı yollu Samsara'da yanılıp yoldan çııр dönüp duran” [BTT XIII, Avalokiteśvara, 27] (Zieme, 1985, s. 123).

\subsection{2. az- yaz-}

'Yoldan çıkmak, şaşırmak' anlamı gelen az- sözcüğü Karahanlı Dönemi eserlerinde de kullanılmıştır. Kutadgu Bilig'de bu sözcügün yanına, 'şaşırmak, yanılmak' anlamındaki yaz- eylemi getirilerek eş anlamlı bir ikileme oluşturulmuştur. Bu ikilemenin anlamı 'yanılmak, şaşırmak' olarak ifade edilebilir.

[...] sözüg sözledeçi azar hem yazar [...] "Sözü söyleyen yanılır, şaşırır” [Kutadgu Bilig 205] (Arat, 1979, s. 37).

\subsection{3. adrilma- azma-}

Bu ikilemenin unsuru olan azma- eylemi, II. Türk Kağanlığından kalma yazıtlarda olumlu şekliyle geçmemektedir. $\mathrm{Bu}$ da o dönemde az- eyleminin de kullanıldığını göstermektedir. Burada azma- eylemi bir ileri ögedir ve 'yoldan çıkmamak, sapmamak' anlamını karşılamaktadır.

[...] kay yorıp éltériş kaganka adrılmadok yayılmadok teyri bilge kaganta adrılmalım azmalım téyin ança ütledim [...] "Baba, ilerleyip Elteriş Kağan'dan ayrılmadığı, hata yapmadığı, Aziz Bilge Kağan'dan ayrılmayalım, doğru yoldan çıkmayalım" diye öylece öğüt verdim." [O K 3] (Aydın, 2017, s. 125).

\subsection{4. azıp kal-adril-}

Bir diğer ikileme ise E 10 numaralı Yenisey bölgesi yazıtı olan Elegest I yazıtında geçen azıp kal-adrıl-ikilemesidir. Bu ikilemeyi oluşturan unsurlardan her ikisi de kazandıkları mecazî 'ölüm' anlamıyla dikkat çekmektedir. Yenisey bölgesi yazıtlarının tamamında ve bazı Dağlık Altay Cumhuriyeti ile Kırgızistan yazıtında, adrıl- 
eylemi mecazî bir anlam kazanarak 'kişinin bu dünyadan ve sevdiklerinden ayrılması; ölmesi' anlamında kullanılmıştır. Böylelikle adrll- ve az- eylemleri, eş anlamlı bir ikileme oluşturmuştur.

élim utuşııa azıp kala<y>ın adrılayın [...] "Yurdum uğruna çekip gideyim, ayrılayum (öleyim)” [E 10. Elegest I, 9] (Aydın, 2019, s. 65). ${ }^{9}$

\section{SONUÇ}

Dış dünyada var olan sınırsız sayıda varlığın, diğerlerinden kendilerini ayıracak bir ada sahip olmaları gerekmektedir. Diller, sınırı olmayan söz konusu varlıklara ad bulma konusunda, temelde seslerden faydalanır. Ancak bir dilin üretebileceği ses sayısı 45-50 dolayındadır. $\mathrm{Bu}$ durumda, diller bu sinırlı sayıda sesi kullanarak sinırsız sayıdaki kavrama ad vermek zorunda kalır.

Sözü edilen zorunlulukta, diller farklı yollara başvurmaktadır. Dillerin kullandıkları bu yöntemlerden en etkilisi belki de sözcükler arasında kurulan anlam ilişkileridir. Sözcükler arasında kurulan eş seslilik, eş anlamlılık ve hatta zıt anlamlılık bağları sayesinde diller, sözü edilen sinırlılıkta yeni kavramlara ad bulabilme imkânına kavuşmaktadır. Ayrıca sözcüklerin tek başına kazandıkları terim, yan ve mecaz anlamlar da bu kapsamda değerlendirilmektedir. Sözcük kökleri de ayrıca ortak kök veya sesteş kök özelliği göstermekte, bu da aynı kökün hem eylem hem de ad olarak kullanılabilme imkânını sağlamaktadır. Bu anlamsal çatallaşma ve ortaklıklar üzerinden, diller ayrıca ikilemeler de kurmaktadır. İkilemeler, üstlendikleri anlatımı güçlendirme ve sözü güzelleştirme fonksiyonlarının yanında, eldeki sesleri ve sözleri kullanarak yeni kavramlar türetme noktasında da katkı sağlamaktadır.

Dillerin kullandığı bu mekanizmalardan pek çoğu, eski Türkçede sıklıkla kullanılan $a z$ sözcüğü üzerinde de işlemektedir. $A z$ sözcüğü öncelikle sesteş kök niteliğindedir. Yazılış itibarıyla aynı olan $a z$ adı ile $a z$ - eylemi arasında, anlamsal hiçbir bağlantı yoktur. $A z$ sözcüğü yalnızca ad olarak dahi dört farklı anlamı karşılamaktadır. Az sözcüğü ad olarak yan anlamlar kazanmış olmanın yanında, Eski Türkçe Dönemi'nde altı farklı ikilemenin de unsuru olmuştur. Böylelikle $a z$ sözcügü ad olarak pek çok anlamsal boyut kazanmıştır. Az- eylemi de Eski Türkçe Dönemi’nde iki farklı anlamı karşılamaktadır. Bu anlamlardan bir tanesi olan mecazî 'ölüm' anlamı hayli dikkat

\footnotetext{
${ }^{9}$ Kormuşin vd. 2016, s. 71'de aynı satır élim utsı̇a bir kılnu (...m kunçuyım ... şa er $y^{1}$ girmen) erdi ayıt-a "Devletimin zaferi için ....yaparak.... oldum. Ne acı!" şeklinde okunmuş ve anlamlandırılmıştır.
} 
çekicidir. Kötü izlenimleri olan ölüm olayının, 'kişinin sevdiklerinden ayrılması, bu dünyadan çekip gitmesi, yolunu şaşırarak kaybolması' şeklinde ifade edilmesi, Türk dilinin henüz Eski Türkçe Dönemi’nde dahi ne derece işlenmiş bir dil olduğunun başka bir göstergesidir. Türk dilinin ilk yazılı belgelerinde kullanılan azıp kal-adrl- ikilemesinin her iki unsuru da kendi temel anlamları dışında mecazî bir anlam kazanmıştır. Yani sözcükler hem mecazî anlamlar kazanmış hem de kazanılan bu mecazî anlamların aynılığından hareketle eş anlamlı bir ikileme oluşturmuştur. Bu da gösteriyor ki Türk dili 8. yüzyıldan çok daha öncesinde bu tip bir manevrayı yapabilecek olgunluğa ulaşmıştır.

$A z$ sesteş kökünün hem ad olarak hem eylem olarak kazandığı farklı anlamlar, eski Türkçenin bütünlüğü içerisinde, bağlamlarıyla birlikte ortaya konulmuştur. Eski Türkçe kavramıyla kastedilen elbette Orhon, Uygur ve Karahanlı devirleridir. Yapılan bu çalışma bu yönüyle araştırmacılara, bir sözcüğün, o dilin çağdaş lehçeleri arasında görülebilecek farklılık ve aynılıklarını sezebilme imkânını sunmaktadır. Dahası aynı sözün, bir dilin tarihsel dönemleri içerisinde, ne gibi değişimlerle devamlılığını sağladığı, kullanımdan düştüğü veya ne tip anlamsal/yapısal çatallaşmalara uğradığı da bu çalışmayla ortaya konulmuştur.

\section{KAYNAKÇA}

Aalto, P. (2000). Orhon Yazıtlarındaki At İsimleri Üzerine. Türk Dili Dil ve Edebiyat Dergisi, 2000 / II, S. 587, 453-457.

Ağakay, M. A. (1953). İkizlemeler Üzerine I-II. Türk Dili Dergisi, C. II, S. 16-17.

Ağakay, M. A. (1954). Türkçede Kelime Koşmaları. Türk Dili Araştırmaları Yıllığı Belleten, 97-104.

Aksan, D. (2014). En Eski Türkçe'nin İzlerinde: Orhun ve Yenisey Yazıtları Üzerinde Sözcükbilim, Anlambilim ve Biçembilim Incelemelerinin Aydınlattı̆̆ Gerçekler. İstanbul.

Aktan, B. (2008). Divanü Lûgati’t-Türk'ün Söz Varlığında Yer Alan İkilemeler. Selçuk Üniversitesi Türkiyat Araştırmaları Dergisi, S. 28, 1-12.

Akyalçın, N. (2007). Türkçe Íkilemeler Sözlüğü. (1. Bask1), An1 Yayıncilık, Ankara.

Alimov, R. (2014). Tanrı Dă̆ı Yazıtları Eski Türk Runik Yazıtları Üzerine Bir Inceleme. (1. Baskı), Kömen Yayınları, Konya. 
Alyılmaz, C. (1994). Orhun Yazıtları'nın Söz Dizimi. Atatürk Üniversitesi Yayınları, Erzurum.

Alyılmaz, C. (2004). Eski Türkçenin Söz Varlı̆̆ının Düz ve Ters Dizimi. Kurmay Basım Yayın Dağıtım, Ankara.

Alyılmaz, C. (2005). Orhun Yazıtları'nın Bugünkü Durumu. Kurmay Basım Yayın Dağıtım, Ankara.

Alyılmaz, C. (2008). (Kök)türk Harfli Yazıtların İzinde. Karam Yayınları, Ankara.

Alyılmaz, S. (2013). Güncel Türkçe Sözlük’te Yer Alan Argo Nitelikli Kavram İşaretleri. Leyla Karahan Armağanı, 165-192.

Arat, R. R. ve Eberhard, W. (1936). Türkische Turfan Texte VII. ABAW, Berlin.

Arat, R. R. (1979). Kutadgu Bilig, I Metin. Türk Dil Kurumu Yayınları, Ankara.

Arat, R. R. (1991). Eski Türk Şiiri. (3. Baskı), Türk Tarih Kurumu, Ankara.

Arat, R. R. (2006). Edib Ahmed B. Mahmud Yükneki, Atabetü'lHakayı. Türk Dil Kurumu Yayınları: 142, Ankara.

Aydın, E. (2015). Yenisey Yazıtları. (1. Baskı), Kömen Yayınları, Konya.

Aydın, E. (1997). Orhon Yazıtlarında Hendiadyoinler. Türk Dil Kurumu Türk Dili Dergisi, S. 577, 417-421.

Aydın, E. (2017). Orhon Yazıtları Köl Tegin, Bilge Kă̆an, Tonyukuk, Ongi, Küli Çor. (1. Baskı), Bilge Kültür-Sanat Yayınları, İstanbul.

Aydın, E. (2018). Uygur Yazıtlarl. (1. Baskı), Bilge Kültür-Sanat Yayınları, İstanbul.

Aydın, E. (2019). Sibirya'da Türk İzleri Yenisey Yazıtları. Kronik Kitap, İstanbul.

Bang, W. ve Gabain, A. von. (1929). Türkische Turfan Texte I. ABAW, Berlin.

Bang, W. ve Gabain, A. von. (1929). Türkische Turfan Texte II. ABAW, Berlin.

Bang, W. ve Gabain, A. von. (1930). Türkische Turfan Texte III. ABAW, Berlin. 
Bang, W. ve Gabain, A. von. (1930). Türkische Turfan Texte IV. ABAW, Berlin.

Bang, W. ve Gabain, A. von. (1931). Türkische Turfan Texte V. ABAW, Berlin.

Bang, W. vd. (1934). Türkische Turfan Texte VI. ABAW, Berlin.

Barutçu Özönder, S. (2006). Çöyr Yazıtı. Modern Türklük Araştırmaları Dergisi, Cilt 3, Sayı 3, s. 108-124.

Baskakov, N. A., ve Toşçakova, T. M. (1947). Oyrotsko-Ruskiy Slovar/Oçerk Grammatiki Oyrotskogo Yazıka. Moskova.

Caferoğlu, A. (2015). Eski Uygur Türkçesi Sözlüğü. (3. Baskı), Türk Dil Kurumu, Ankara.

Bazin, L. (1993). Quelques remarques d"Epigraphie Turque ancienne. Türk Dilleri Araştırmalarl, 3, s. 33-41.

Bazin, L. (2011). Eski Türk Dünyasında Kronoloji Yöntemleri. çev. Vedat Köken, Ankara: Türk Dil Kurumu Yayınları.

Clauson, G. (1965). Turkish and Mongolian Horses and use of Horses, An Etymological Study. Central Asiatic Journal, Vol. 10, No. 3/4, Proceedings of the VIIth Meeting of the Permanent Internatinnal Altaistic Conference:: 29 Ağustos-3 Eylül 1964, 161-166, Harrassowitz Verlag.

Clauson, G. (1972). An Etymological Dictionary of Pre-ThirteenthCentury Turkish. Oxford: Oxford University.

Çağatay, S. (2008). Uygurcadaki Hendiadyoinler. Prof. Dr. Saadet Çağatay'ın Yayımlanmamış Tüm Makaleleri, C. I., Ayaz Tahir Türkistanlı İdil-Ural Vakfi, İstanbul.

Çetin, E. (2017). Altun Yaruk Sekizinci Kitap (Berlin Bilimler Akademisindeki Metin Parçaları, Karşılaş̧tırmalı Metin, Çeviri, Açıklamalar, Dizin). (1. Baskı), Karahan Kitabevi, Adana.

Doerfer, G. (1963-1975). Türkische und mongolische Elemente im Neupersischen I-IV. Akademie der Wissenschaften und der Literatur, Veröffentlichungen $d r$ orientalischen Kommission 10, Wiesbaden.

Doerfer, G. (1995). Türkische Farbbezeichnungen und Pferdezucht. Central Asiatic Journal, Vol. 39, No. 2, 208-227, Harrassowitz Verlag. 
Ercilasun, A. B. ve Akkoyunlu, Z. (2015). Kâşgarlı Mahmud Dîvânu Lugâti't-Türk (Giriş - Metin - Çeviri - Notlar - Dizin). (2. Bask1), Türk Dil Kurumu Yayınları, Ankara.

Ercilasun, A. vd. (1992). Karşılaştırmalı Türk Lehçeleri Sözlüğü I-II. (2. Baskı), Kültür Bakanlığı Yayınları, Ankara.

Erdem, M. D. (2005). Harezm Türkçesinde İkilemeler ve Yinelemeler Üzerine. Bilig, Bahar 2005, Sa. 33, 189-225.

Esin, E. (1965). The Horse in Turkic Art, Central Asiatic Journal, Vol. 10, No. 3/4. Proceedings of the VIIth Meeting of the Permanent Internatinnal Altaistic Conference: 29 Ağustos-3 Eylül 1964 (Aralık 1965), 167-227, Harrassowitz Verlag.

Foy, K. (1899). Studien zur Osmanichen Syntax, Das Hendiadyoin und die Wortfolge ana baba. Mitteilungen des Seminars für Orientalische Sprachen (MSOS), C. II, Böl. II, 1899, 105-136.

Gabain, A. von. (1954). Türkische Turfan Texte VIII. ABAW, Berlin.

Gabain, A. von. (1958). Türkische Turfan Texte IX. ABAW, Berlin.

Gabain, A. von. (1959). Türkische Turfan Texte X. ABAW, Berlin.

Gabain, A. von. (1988). Eski Türkçenin Grameri. (çev. Mehmet Akalın), Türk Dil Kurumu, Ankara.

Gemalmaz, E. (2010). Türkçenin Derin Yapısı (Haz. C. Alyılmaz ve O. Mert). Ankara.

Gülensoy, T. (2007), Türkiye Türkçesindeki Türkçe Sözcüklerin Köken Bilgisi Sözlüğü. Türk Dil Kurumu, Ankara.

Hamilton, J. R. (1998). Lyi ve Kötü Prens Öyküsü. Türk Dil Kurumu Yayınları, Ankara.

Hatipoğlu, V. (1981). Türkçede İkilemeler. (2. Bask1), Türk Dil Kurumu Yayınları, Ankara.

Hazai, G. ve Zieme, P. (1970). Fragmente der uigurischen Version des 'Jin'gangjing mit den Gâthâs des Meister Fu'. Nebst einem Anhang von T. Inokuchi. Berlin (Berliner Turfan-Texte I).

Hirik, E. (2018). Türkçede Tekrarlı Yapı Sınıfları. Türkiyat Mecтuası, 28/2, s. 37-65.

http://www.altay.uni-frankfurt.de/A18/BRBGZ1_X.PNG

(05.10.2018) 


ÇÜTAD
Haziran 2019 $\quad$ Eski Türkçe $A z$ Sesteş Kökü Üzerine

http://www.altay.uni-frankfurt.de/A18/A18_O.HTM (05.10.2018)

http://www.altay.uni-frankfurt.de/A7/MENSOK1_X.PNG

(05.10.2018)

http://www.altay.uni-frankfurt.de/A7/A7_O.HTM (05.10.2018)

Kara, G., ve Zieme, P. (1976). Fragmente tantrischer Werke in uigurischer Übersetzung. Akademie Verlag Berlin (Berliner Turfan-Texte VII).

Kara, G ve Zieme, P. (1977). Die uigurischen Übersetzungen des Guruyogas “Tiefer Weg” von Sa-skya Panđita und der Majjuśīnāmasamgīti. Akademie Verlag Berlin, Berlin (Berliner Turfan-Texte VIII).

Kaya, C. (1994). Uygurca Altun Yaruk, Giriş, Metin ve Dizin. Türk Dil Kurumu Yayınları, Ankara.

Kormuşin, I. vd. (2016). Yenisey-Altay-Kırgızistan Yazıtları ve Kâğıda Yazılı Runik Belgeler. (1. Baskı), BilgeSu Yayınları, Ankara.

Malov, S. Ye. (1952). Yeniseyskaya pis'mennost' Tyurkov, textı $i$ perevodi. Moskva-Leningrad.

Mert, O. (2009). Ötüken Uygur Dönemi Yazıtları'ndan Tes - Tariat Şine Us. Belen Yayıncılık, Ankara.

Mert, O. (2015). Köli Çor Yazıtı ve Anıt Mezar Kompleksi. Atatürk Üniversitesi Yayınları, Erzurum.

Nadelyayev, V. M. vd. (1969). Drevnetyurkskiy Slovar'. Leningrad.

Orkun, H. N.. (2011). Eski Türk Yazıtları. (3. Baskı), Türk Dil Kurumu, Ankara.

Ölmez, M. (2017). Eski Uygurca İkilemeler Üzerine. Belleten, 65 (2), 243-311.

Ölmez, Z. (1997). K. Kutadgu Bilig'de İkilemeler (1). Türk Dilleri Araştırmaları, S. 7, 19-40.

Ölmez, Z. K. (1998). Kutadgu Bilig'de İkilemeler (2). Bahşi Ögdisi 60. Doğum Yllı Dolayısıla Klaus Röhrborn Armağanı, (1. Baskı), eds. Mehmet Ölmez - J. Peter Laut, Simurg Yayıncılık. [Türk Dilleri Araştırmaları Dizisi: 21], İstanbul-Freiburg.

Rozental, D. ve Telenkova, M. A. (1976). Slovar Spravoçnik. Lingvistiçeskix Terminov, Moskova. 
Röhrborn, K. (1971). Eine uigurische Totenmesse. Text, Übersetzung, Kommentar. Berlin (Berliner Turfan-Texte II).

Röhrborn, K. (1977). Uigurisches Wörterbuch. Sprachmaterial der vorislamischen türkischen Texte aus Zentralasien, Lieferung I, aagrtg. Franz SteinerVerlag GMBH, Wiesbaden.

Sağol G. (1995). Tarihî Şivelerde At Donları. Türk Kültüründe At ve Çağdaş Atçılık, Türkiye Jokey Kulübü, 126-146, İstanbul.

Sev, G. (2004). Divanü Lûgati’t-Türk'te İkilemeler. Türk Dili Dil ve Edebiyat Dergisi, C. LXXXVIII, Ekim 2004, S. 634, 497-510.

Şen, S. (2002). Eski Uygur Türkçesinde İkilemeler. (Yayımlanmamış yüksek lisans tezi), Ondokuz Mayı Üniversitesi Sosyal Bilimler Enstitüsü Türk Dili ve Edebiyatı Anabilim Dalı, Samsun. (Türkiye).

Tekin, Ş. (1976). Uygurca Metinler II Maytrısimit. Sevinç Matbaası, Ankara.

Tekin, Ş. (1980). Maitrisimit Nom Bitig, Die Uigurische Übersetzung eines Werkes der buddhistischen Vaibhāsika-Schule. 1. Teil: Transliteration, Übersetzung, Anmerkungen, 2. Teil: Analytischer und lücklaufiger Index. Berliner Turfantexte IX, Berlin.

Tekin, T. (1997). The first Altınköl Inscription, Turkic Languages 1 / 2, 210-226.

Tekin, T. (2003). Orhon Türkçesi Grameri. (2. Bask1), TDAD, İstanbul.

Tıbıkova, L. vd. (2012). Katalog Drevnetyurkskih Runiçeskix Pamyatnikov Gornogo Altaya. (1. Bask1), Gorno-Altaysk, GornoAltaysk Gosudarstvennıy Universitet.

Toparlı, R. vd. (2007). Kıpçak Türkçesi Sözlüğü. (2. Baskı). Türk Dil Kurumu, Ankara.

Toprak, F. (2005). Harezm Türkçesinde İkilemeler. Türk Dünyası Incelemeleri Dergisi, Ege Üniversitesi Türk Dünyasl Araştırmaları Enstitüsü, C. V, S. 2, 277-292.

Tuna, O. N. (1983). Türkçenin Sayıca Eş Heceli İkilemelerinde Sıralama Kuralları ve Tabiî Bir Ünsüz Dizisi. Türk Dil Kurumu Türk Dili Araştırmaları Yıllı̆̆ı Belleten 1982-1983, 163-228.

Üstünova, K. (1998). Dede Korkut Destanlarında Aralıklı İkilemeler. Türk Dili, Türk Dil Kurumu, S. 557, 464-470. 
Wilkens, J. (2007). Edition des alttürkisch-buddhistischen Kşanti Kllguluk Nom Bitig. Berlin (Berliner Turfan-Texte XXV).

Yıldırım, F. (2017). Irk Bitig ve Orhon Yazılı Metinlerin Dili. (1. Baskı), Türk Dil Kurumu Yayınları, Ankara.

Zieme, P. (1975). Manichäisch-türkische Texte. Berlin (Berliner Turfan-Texte V).

Zieme, P. (1985). Buddhistische Stabreimdichtungen der Uiguren. Berlin (Berliner Turfan-Texte XIII). 